\title{
Deciduous or evergreen: Does it make a difference to understorey pasture yield and riparian zone management?
}

\author{
I.L. POWER, M.B. DODD and B.S. THORROLD \\ AgResearch, Ruakura Research Centre, Private Bag 3123, Hamilton \\ email: ian.power@agresearch.co.nz
}

\begin{abstract}
This paper uses data from an artificial shade trial to compare the impacts of shade duration on pasture production with deciduous and evergreen tree species. Results indicated that light quantity was not the only main limiting factor in understorey pasture yield. At low levels of shade $(<40 \%)$, pasture relative yields under the nitrogen-fixing tree, Acacia melanoxylon, were greater than relative yields under corresponding levels of artificial shade. We concluded that when comparing tree understorey pasture yields, the variation between tree species was greater than the variation between deciduous and evergreen tree groups. For a deciduous tree species to be effective in mitigating pasture yield during the leaf-free period, they must be leaf-free for longer than 4 months. Additionally, in riparian zone plantings the amount of shading required to reduce water temperatures to desired levels for invertebrate stream life is too high to maintain pasture cover. Selection and management of appropriate tree species to reduce shading intensities is required to maintain adequate understorey pasture yield and density. Further work on deciduous tree species is required to further understand the interactions between understorey pasture yield, duration of shade and tree species.
\end{abstract}

Keywords: Acacia melanoxylon, agroforestry, artificial shade, Eucalyptus nitens, light, Poplar spp.

\section{Introduction}

The use of trees in pastures should be an integral part of addressing sustainability issues in New Zealand pastoral farming. The key roles of trees on farms are as woodlots, shelter for stock, soil conservation and riparian management (as a nutrient sink and for stream bank stability). Shading is a direct consequence of planting trees with resulting negative impacts on pasture quality and persistence (Power et al. 1999). The ability to maintain pasture quality and persistence is important for minimising soil erosion and maintaining nutrient filtering capacity (Smith et al. 1987).

During the 1980s and 1990s a considerable amount of work was carried out in New Zealand looking at the effects of Pinus radiata on soil nutrient levels and understorey pasture yield and composition (Percival et al.1984; Percival \& Knowles 1988). More recent studies have focused on alternative tree species such as Acacia melanoxylon and Eucalyptus nitens (Power et al. 1999), Poplar spp. (Guevara-Escobar et al. 1997; Wall 1997) and Salix matsudana (Gilchrist et al. 1993), with particular interest in broadleaf deciduous tree species and nitrogen $(\mathrm{N})$-fixing tree species. Pasture grazing under tree canopies is subject to a number of variables, including competition for moisture and nutrients, smothering by litter fall and animal influences as well as shading. The compound effect of these influences is to restrict our ability to predict pasture yield and to identify what are the main influences on pasture yield for any particular tree species. One of the advantages of using a broadleaf deciduous tree species in silvopastoral systems is thought to be the leaf-free period over winter/early spring where less decline in pasture yield may occur (Power et al. 1999). The impact of Poplar spp. on pasture yield has only recently been studied in depth (Guevara-Escobar et al. 1997). In that study, the seasonal influences of increased light after leaf fall on pasture yield were influenced by the smothering effect of the fallen leaves.

Water temperatures in streams passing through open pasture have been shown to be higher than that required to sustain populations of many indigenous invertebrate and fish species (Rutherford et al. 1999). Shading of streams by riparian vegetation is one way to lower stream water temperatures and restore the native invertebrate and fish populations. A shading intensity of $70 \%$ or more is required to achieve desired stream water temperatures (Rutherford et al. 1999). The use of trees in the riparian zone could provide sufficient shade to achieve desired shading intensities. Rutherford et al. (1999), also suggested that the use of deciduous trees could allow for pasture recovery during the autumn and winter months when leaf cover had disappeared and streams did not require additional shading to meet critical temperature targets. 
In order to assess the impact of shading intensity and shade duration on pasture growth we conducted a field experiment using artificial shade at a range of shading intensities and durations of shade, covering newly sown pasture. Some of the results from this study were then compared to pasture yields under deciduous and evergreen trees (from the literature), to assess whether shading was the dominant effect on pasture yield.

\section{Method}

\section{Site preparation}

The area chosen for the artificial shade trial was located in the Barkers block of Whatawhata Research Centre, State Highway 23 between Hamilton and Raglan, New Zealand. The site is $960 \mathrm{~m}^{2}$ in area and has a $10-15^{\circ}$ slope with a westerly aspect. The existing pasture was removed by spraying with glyphosate at the rate of $10 \mathrm{l} /$ ha, then cultivated to a $150-200 \mathrm{~mm}$ depth with a rotary hoe. After 4 weeks, the area was sprayed again to remove germinated seedlings and pasture regrowth. The site was then levelled and consolidated with sheep treading to aid compaction before sowing. In early May $1994,5 \mathrm{~kg} / \mathrm{ha}$ of Ellett ryegrass (Lolium perenne), $4.2 \mathrm{~kg}$ / ha of Massey Basyn yorkshire fog (Holcus lanatus), $3 \mathrm{~kg} / \mathrm{ha}$ of Huia white clover (Trifolium repens) and $7.5 \mathrm{~kg} / \mathrm{ha}$ of Maku lotus (Lotus pedunculatus) was sown with a hand spreader. Three days after sowing, the site was again treaded with sheep to bury the seed. In late June, once the pasture was established the site was rolled twice with a lightweight roller and 40 plots of $2 \mathrm{~m}^{2}$ pegged out. A single spraying with MCPB was conducted at this time to eliminate a minor thistle problem that had occurred since cultivation, thus ensuring all plots started the trial on an even footing.

\section{Shade covers}

Frames $(1.8 \mathrm{~m} \times 2.0 \mathrm{~m})$ were covered with shade cloth and/or a lighting filter and placed over selected plots providing a range of nominal light levels $(0-83 \%$ shading) and Red to Far-Red ratios (0.36-1.0). Open pasture plots were not covered. The impact of Red to Far-Red ratios on pasture yield is not discussed in this paper. To eliminate the effects of sidelight reaching the plots, a skirting of shade cloth providing $80 \%$ shade was attached to the side of the frames and hung down to ground level. The frames were randomly placed over the trial area and secured in place $400 \mathrm{~mm}$ above the pasture surface. Placement and removal of the frames providing three shade durations [12 months: 8 months; (October-May inclusive): 4 months; (November-February inclusive)], simulating the effects of a deciduous tree without the impact of fallen leaves and competition for moisture and nutrients. There was no replication of individual treatments.

\section{Measurements}

The trial ran for 18 months with the plots being harvested at monthly intervals throughout spring, summer and autumn with two 6-weekly cuts in the winter. Two harvests were made in spring prior to the placement of the shade covers to obtain initial pasture yield data. Pasture dry matter yield, was measured monthly with a one off measurement of photosynthetically active radiation (PAR), in August 1996 using a PAR line sensor. Because the PAR measurements were similar to the calculated shading of the plots from the shade cloth and lighting filters the nominal measurements were used in the analysis of the data. Pasture dry matter yield is expressed as treatment yield relative to the open pasture, where open pasture equals 100\% (Power et al. 1999).

To ensure that soil moisture was non-limiting a permanent sprinkler watering system was put in place and watering controlled electronically. Sufficient water was applied to remove any water stress and periodic volumetric (v/v\%) soil moisture contents were measured using Time Domain Reflectometry (TDR) (Topp et al. 1980). Soil moisture was measured in all plots at 0 $15 \mathrm{~cm}$ depth at 4- to 6-weekly intervals by manually inserting the probes at each measurement time.

The results from this trial were compared to trials conducted under A. melanoxylon and E. nitens at Te Kuiti (Power et al. 1999) and under poplars at Kiwitea (Devkota et al. 2000) and Pohangina Valley (GuevaraEscobar et al. 1997). Light levels measured under the three species in these studies ranged from $10-65 \%(A$. melanoxylon), 8-48\% (E. nitens) and 38-75\% (Poplar spp.). Extra A. melanoxylon and E. nitens data have been collected since the study of Power et al. (1999) and have been included in the analysis for this paper.

\section{Statistical analysis}

Bayesian smoothing routines (Upsdell 1994) were used to compare relationships between pasture relative yields and shading treatments, hence no replication was required. The bands represent $83 \%$ confidence intervals, hence where confidence intervals don't overlap, curves are significantly different at the $5 \%$ level. The curves in Figures 1 and 3 have been forced through the point where relative yield equals $100 \%$.

\section{Results and discussion}

The artificial shade trial showed that as shading intensity increased, pasture relative yields decreased for each shade duration treatment (Figure 1). Pasture 
relative yield decreases were similar on an annual basis for the 12-month and 8month shading treatments but lower for the 4-month shading treatment. Yield differences between durations of shade were greatest at high levels of shade and least at low levels of shade.

During the period when shading was removed, pasture relative yields recovered for the 4-month shading treatment at $60 \%$ shade, but did not recover for the 8-month shading treatment (Figure 2). At levels of shade greater than $60 \%$, pasture yield recovery patterns were similar to $60 \%$ shade. At levels of shade lower than $60 \%$, pasture yield responses were similar for all three shade durations.

Data collected from under the poplars at the Pohangina Valley site (GuevaraEscobar et al. 1997), showed that at shading levels of between 40 and $90 \%$ of that of the open pasture, pasture yields did not appear to recover during the leaffree period (winter). This was consistent with the artificial shade trial results. Additionally, smothering by autumn leaf fall (Guevara-Escobar et al. 1997), and or reduced light reaching the pasture due to shading by the defoliated tree trunks and branches may also impact on pasture recovery after leaf fall. Devkota et al. (2000) measured a $7-39 \%$ light reduction compared to open pasture during the leaf-free period over winter and McElwee (1998) estimated that 30\% of the light reduction occurring when the trees were in full leaf was due to shading by the tree trunks and defoliated branches.

Pasture relative yields for 12 months of artificial shade was similar to that measured under $E$. nitens at levels of shade less than approximately $42 \%$ and greater at shading levels greater than $42 \%$ (Figure 3 ). Additionally, pasture relative yields under A. melanoxylon were greater than under artificial shade at levels of shade between approximately $10 \%$ and $39 \%$ (Figure 3 ). At levels of shade greater than approximately $58 \%$, pasture relative yields were greatest under artificial shade. Reasons why pasture relative yields under $A$. melanoxylon were greater than those measured under artificial shade at low levels of shade may be in part due to the $\mathrm{N}$ fixing capabilities of the Acacia and higher $\mathrm{N}$ availability in the understory
Figure 1 Effect of duration of shade on annual pasture relative yield $(\mathrm{RY} \%)$ from the artificial shade trial.

(4 months shade $=\square Z Z Z Z Z, 8$ months shade $=\$ 1111,12$ months shade $=\square \amalg \amalg \amalg)$

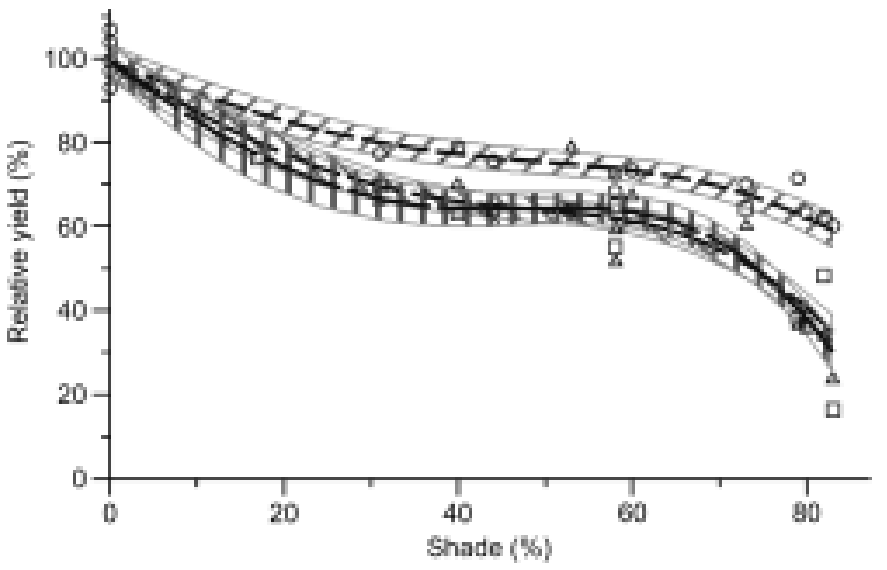

Figure $\llbracket 2$ Effect of duration of shade on pasture relative yield recovery at $60 \%$ shading intensity for the artificial shade trial. (Confidence intervals are not given for the 12-month shade duration treatment, as they are similar to the 8-month shade duration treatment).

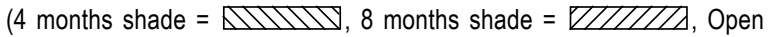
Pasture = पШ口П)

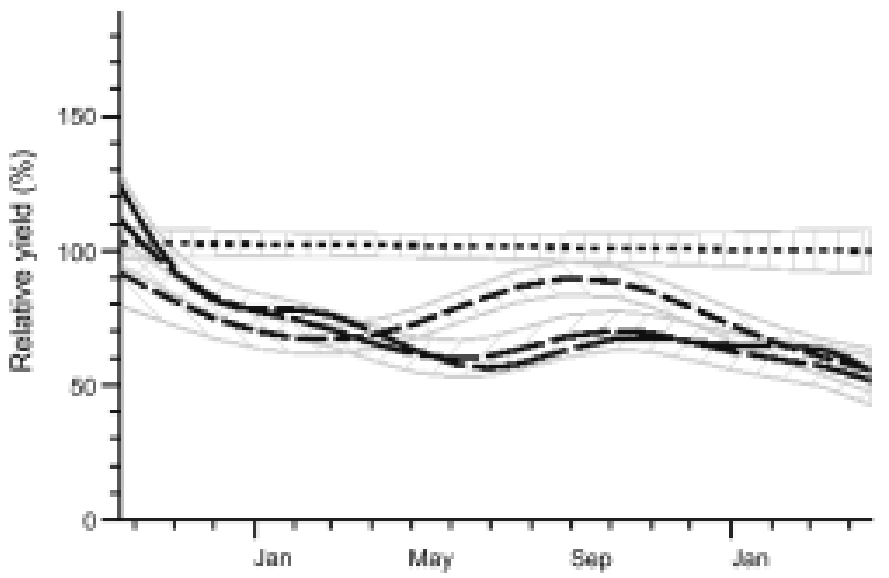

soil (Power 1997). Tree effects not present under artificial shade, such as smothering by leaf litter fall, competition for nutrients and water and allelopathic effects may account for reduced relative yields under $E$. nitens at levels of shade greater than $42 \%$ and $A$. melanoxylon at levels of shade greater than $58 \%$.

\section{What was learnt from this study in relation to agroforestry field situations?}

This study clearly demonstrated that at low shade levels $(10 \%$ to $39 \%)$, in this moist, fertile environment, the amount of shade is not the only limiting factor 
influencing pasture yield. With the addition of extra $\mathrm{N}$, such as from the $\mathrm{N}$ fixing tree A. melanoxylon, pasture yields may significantly exceed those from shade alone with other tree factors also having an influence on understorey pasture yield. These results indicate that although shading is a major limiting factor to understory pasture yield, influences other than shade such as moisture and nutrient competition, allelopathic effects and smothering are also operating under the trees. It is also clear that these influences are tree species dependent as different tree species have varied yield responses to similar levels of shade.

One of the objectives of the artificial shading trial was to compare the effects of deciduous trees on understorey pasture yields and pasture recovery during the 'leaf-free' period over autumn and winter. The lack of pasture recovery for the 8 months of artificial shade during the shade-free period over autumn and winter resulted in similar pasture yields to 12 months of shade. For a deciduous tree species to have an advantage compared to an evergreen tree species in understorey pasture yield, the leaf-free period must be greater than 4 months. This indicates that because deciduous tree species tend to be in leaf for 7 to 9 months, the advantages of utilising a deciduous tree species compared to an evergreen tree species is not necessarily a deciduous versus evergreen tree issue but a tree species issue.

Shading of streams to lower water temperatures and restore indigenous invertebrate and fish populations is also an important consideration in any catchment management programme that seeks to be sustainable (Rutherford et al. 1999). At shading intensities of $70 \%$, the amount of shade considered to benefit fresh water fauna (Rutherford et al. 1999), pasture relative yields could be reduced to approximately $53 \%$ of the open pasture (based on Figure 1), without the added influence of other tree effects reducing yields even further. To provide maximum shading of waterways to reduce stream water temperatures while maintaining pasture production, the benefits of utilising a deciduous tree species is less important than actual tree species selection, whether deciduous or evergreen. Strategic planting of trees to shade exposed stream reaches, tree pruning, the planting of the north banks of streams only and the width of riparian plantings are important considerations which may help increase light to understorey riparian zones.

\section{Conclusions}

- Tree characteristics that influence shading intensity of the understorey pasture, such as tree-stocking rate and canopy architecture, are the main limiting factors on understorey pasture yields.

- At low shade levels, competition for nitrogen may also be an important limiting factor on pasture understorey yield with pasture yields under Nfixing trees species, such as A. melanoxylon, being greater than those under non $\mathrm{N}$-fixing tree species.

- There is no advantage to pasture yield of utilising a deciduous tree species compared to an evergreen tree species unless the seasonal pattern of leaf fall creates a leaf-free period of greater than 4 months.

- Variation between the effects of individual tree species on understorey pasture yield is greater than the variation in effects between deciduous and evergreen tree groups.

- The amount of shading required to reduce stream water temperatures to desired levels is too high to maintain sufficient pasture cover.

- In order to maintain adequate understorey pasture yield and density, selection and management of appropriate tree species to reduce shading intensities is required.

\section{ACKNOWLEDGEMENTS}

The authors acknowledge the input of Dr Martin Upsdell, AgResearch, Ruakura for his advice and work on the analysis. We also acknowledge Forest Research for allowing us to utilise their existing trials for this study and Mr Garth Cumberland who made available to us his property at Te Kuiti. 


\section{REFERENCES}

Devkota, N.R.; Wall, A.J.; Kemp, P.D.; Hodgson, J. 2000. Relationship between canopy closure and pasture production in deciduous tree based temperate silvopastoral systems. Proceedings of the XVIII International Grassland Congress: 652-653.

Gilchrist, A.N.; Dez Hall, J.R.; Foote, A.G.; Bulloch, B.T. 1993. Pasture growth around broad leaved trees planted for grassland stability. Proceedings of the XVII International Grassland Congress: 2062-2063.

Guevara-Escobar, A.; Kemp, P.D.; Hodgson, J.; Mackay, A.D.; Edwards, W.R.N. 1997. Case study of a mature Populus delotides-pasture system in a hill environment. Proceedings of the New Zealand Grassland Association 59: 179-185.

McElwee, H. 1998. The economic, environmental and social impacts of afforestation of hill country farmland on the east coast. Master of Management Studies Thesis, University of Waikato, Hamilton, New Zealand. 147 pp.

Percival, N.S.; Gee, T.M.; Steele, K.W. 1984. Effects on soil fertility of Pinus radiata on Farmland. pp. 49-52. In: Proceedings of a technical workshop on agroforestry. Ed. Bilbrough GW. Dunedin, New Zealand.

Percival, N.S.; Knowles, R.L.; 1988. Relationship between radiata pine and understorey pasture production. pp. 152-164. In: Proceedings of the Agroforestry Symposium Rotorua, 1986, FRI Bulletin No 139.
Power, I.L. 1998. The effects of Acacia melanoxylon on soil nitrogen levels and nitrogen availability. Master of Science Thesis, University of Waikato, Hamilton, New Zealand. 169 pp.

Power, I.L.; Dodd, M.B.; Thorrold, B.S. 1999. A comparison of pasture and soil moisture under Acacia melanoxylon and Eucalyptus nitens. Proceedings of the New Zealand Grassland Association. 61: 203-207.

Rutherford, J.C.; Davies-Colley, R.J.; Quinn, J.M.; Stroud, M.J.; Cooper, A.B. 1999. Stream Shade. Towards a restoration strategy. Department of Conservation, Wellington, New Zealand.

Smith, C.M. 1987. Sediment, phosphorus, and nitrogen in channelised surface run-off from a New Zealand pastoral catchment. New Zealand Journal of Marine and Freshwater Research 21: 627-639.

Topp, G.C.; Davis, J.L.; Annan, A.P. 1980. Electromagnetic determination of soil water content measurements in coaxial transmission lines. Water Resources Research 16: 574-582

Upsdell, M.P. 1994. Bayesian smoothers as an extension of non-linear regression. New Zealand Statistician 29: 66-81.

Wall, A.J.; Mackay, A.D.; Kemp, P.D.; Gillingham, A.G.; Edwards, W.R.N. 1997. The impact of widely spaced soil conservation trees on hill pastoral systems. Proceedings of the New Zealand Grassland Association Conference 59: 171-177. 